\title{
РОЛЬ МАКРОФАГОВ В ОЦЕНКЕ ЭФФЕКТИВНОСТИ ИММУНОТЕРАПИИ ХРОНИЧЕСКОГО ЭНДОМЕТРИТА
}

\section{THE ROLE OF MACROPHAGES IN ASSESSING THE EFFECTIVENESS OF IMMUNOTHERAPY OF CHRONIC ENDOMETRITIS}

\section{E. Kosykh \\ I. Korotkikh}

Summary. The article considers such an important aspect as the violation of immunomorphological changes in the endometrium during the development of chronic endometritis (CE).

CE, in turn, is the most common cause of the development of female infertility.

Of particular importance in the process of implementing changes in the immune response for this pathology is macrophages, an increase in which in the endometrium of women can characterize the intensity of the inflammatory process in tissues and serve as a prognostically unfavorable factor for normal adhesion and blastocyst implantation.

The inclusion of Derinat in the complex therapy of chemotherapy helps to restore the main links of the immune system, creating the prerequisites for the effective implementation of in vitro fertilization (IVF).

Keywords: chronic endometritis, infertility, immunity, immune response, endometrium, macrophages, in vitro fertilization (IVF).

\section{Актуа^ьность}

B настоящее время одной из ведущих причин женского бесплодия являются хронические воспалительные патологии органов малого таза, и в частности, воспаления внутренней оболочки матки - хронический эндометрит $[1,2]$. По результатам последних исследований заболеваемость хроническим эндометритом у женщин активного репродуктивного возраста может достигать 66,3\% среди всей воспалительной нозологии органом малого таза [2,3]. Недавно выполненные исследования свидетельствуют о том, что ХЭ связан с бесплодием и невынашиванием беременности; он был выявлен у 12-46\% бесплодных пациентов, у $30 \%$ женщин с неудачно выполненным ЭКО.

Важное значение в развитии хронического воспалительного процесса в эндометрии отводится возникновению
Косых Екатерина Владимировна

Аспирант, ФГБОУ ВО Воронежский Государственный Медицинский Университет им. Н. Н. Бурденко ekaterina1991kosykh@gmail.com Коротких Ирина Николаевна

Д.м.н., профессор, ФГБОУВО Воронежский Государственный Медицинский Университет им. Н.Н. Бурденко

Аннотация. В статье рассмотрен такой важный аспект как нарушение иммуноморфологических изменений в эндометрии при развитии хронического эндометрита (ХЭ).

ХЭ в свою очередь является наиболее частой причиной развития женского бесплодия.

Особое значение в процессе реализации изменений в иммунном ответе при данной патологии отводится макрофагам, увеличение которых в эндометрии женщин может характеризовать интенсивность воспалительного процесса в тканях и служить прогностически неблагоприятным фактором для осуществления нормальной адгезии и имплантации бластоцисты.

Включение в комплексную терапию ХЭ препарата Деринат способствует восстановлению основных звеньев иммунитета, создавая предпосылки эффективного проведения экстракорпорального оплодотворения (ЭКО).

Ключевые слова: хронический эндометрит, бесплодие, иммунитет, иммунный ответ, эндометрий, макрофаги, экстракорпоральное оплодотворение (ЭКО).

развития дисбаланса между гормональной и иммунной системами организма, с одной стороны, и патогенами - представителями микробиоценоза с другой $[3,4,5,6]$.

Обострение хронических воспалительных заболеваний органов малого таза может сопровождаться как развитием недостаточности, так и повышением количества регуляторных субпопуляций лимфоцитов, нарушением кооперационных связей между ними, постепенным снижением фагоцитарной функции микрофагов соответственно тяжести и длительности заболевания [7]. Высокая вирулентность, избыточное количество инфекционных агентов, формирование дефектов отдельных звеньев иммунной системы приводят к развитию атипичного воспаления [8,9].

Несмотря на значительное количество исследований, посвященных анализу иммунологических аспектов 
при ХЭ, состояние местного иммунитета эндометрия при инфекционном поражении слизистой оболочки матки продолжает оставаться дискуссионным [10,11,12,13,14].

В литературных данных отмечено, что в пролиферативную фазу на 7-11-й день цикла в эндометрии выявлено достоверное увеличение числа монопитов/ макрофагов (CD14+) и NK-клеток (CD56+). Отмечается незначительное повышение общего числа Т-лимфоцитов (CD3+). Уровни Т-хелперов (CD4+) и Т - супрессоров (CD8+), а также их соотношение не отличаются от показателей у здоровых женщин. Увеличение числа NK-клеток (CD56+) и макрофагов (CD14+) в эндометрии женщин с патологией репродукции характеризует интенсивность воспалительного процесса в ткани и является неблагоприятным фактором, препятствующим нормальной адгезии и имплантации бластоцисты, а также дальнейшему развитию трофобласта. $[8,15,16]$.

Число CD95+-клеток (маркеров апоптоза) значительно превышает аналогичный показатель у здоровых женщин, и свидетельствует о высоком уровне запрограммированной клеточной гибели на фоне хронического воспаления в эндометрии. Отмечено, что перитонеальные макрофаги, выделенные от пациентов с эндометритом, способны вызывать снижение фагоцитарной способности и снижение экспрессии кластера дифференцировки 36 (CD36) [17,18,19].

Дисбаланс подмножеств Т-клеток приводит к аберрантным секрециям цитокинов и воспалению, что приводит к увеличению выраженности симптомов ХЭ. До сих пор неясно, являются ли иммунные клетки первичной причиной и / или стимулируют действия, которые усиливают заболевание; однако в любом случае модулирование действий этих клеток может предотвратить инициацию или прогрессирование заболевания. Необходимы дальнейшие исследования, чтобы углубить пониманиеХЭ и разработать новые подходы к лечению женщин, страдающих этим заболеванием Исходя из вышеперечисленного, важное значение уделяется подбору адекватной терапии, сочетающей в себе свойства иммуномодулятора. В данном аспекте интерес представляет отечественный препарат Деринат ${ }^{\circledR}$, иммуномодулирующий эффект которого обусловлен взаимодействием действующего вещества препарата с патогенраспознающими рецепторами (TLR9), что в свою очередь стимулирует факторы роста эндотелиоцитов и образование новых сосудов.

\section{Цель исслемования}

Изучение роли макрофагов в формировании врожденного иммунитета при хроническом эндометрите на основе клинической эффективности препарата Деринат ${ }^{\circledast}$ (раствор для внутримышечного введения 15 мг/ мл, флакон) в комплексной терапии ХЭ, ассоциированным с бесплодием у женщин репродуктивного возраста.

\section{Материалы и методы иссленования}

Клиническая часть исследования проводилась на базе кафедры акушерства и гинекологии № 1 ФГБОУ ВО «Воронежский государственный медицинский университет ИМ. Бурденко» Министерства здравоохранения Российской Федерации. Лабораторные исследования проводились на базе клинико-диагностической лаборатории БУЗ ВО «Воронежская областная клиническая больница № 1». Патоморфологические исследования осуществлялись в отделении морфологических анализов ГУЗ «Воронежское областное патологоанатомическое бюро. Проведенное исследование инициировалось держателем регистрационного удостоверения препарата Деринат ${ }^{\circledR}$ (ООО «ФармПак», Россия) и соответствовало структуре пострегистрационного исследования эффективности по однородности выборок групп, возрасту, пациентов, полу, частоте заболеваний за период исследования, фоновой патологии.

В исследование было включено 60 пациенток в возрасте от 20 до 41 года, что соответствовало критериям активного репродуктивного возраста с установленным диагнозом: привычное невынашиванием беременности, хронический эндометрит.

К критериям исключения пациенток из исследования относилось: индивидуальная непереносимость применяемой терапии; наличие заболеваний, требующих назначения антибактериальной, противовирусной и иммуномодулирующей терапии и/или хронических заболеваний мочеполовой системы; участие в каких - либо клинических исследованиях в течение предыдущего месяца и/или отказ пациента принимать участие в исследовании. Все больные, включенные в исследование, получали лечение в условиях гинекологических отделений (№ 1, № 2 и № 4) Перинатального центра «Воронежская областная клиническая больница № 1 ».

На протяжении исследования проводилось 9 визитов пациенток (таблица 1). Период наблюдения составил 6 месяцев. Исследовательские группы представлены следующим образом: группа 1 (основная) - 30 пациенток с привычным невынашиванием беременности и хроническим эндометритом в возрасте от 21 до 41 года, которым проводилось стандартное антибактериальное лечение в комплексе с применением препарат Деринат ${ }^{\oplus}$ раствор для внутримышечного введения 15 мг\мл (флакон), производитель 000 «ФЗ Иммуннолекс», Россия) по 5 мл (75 мг) 1 раз в сутки через 48 часов в течение 10 дней, 10 инъекций на курс; группа 2 (контрольная) -- 30 пациенток с привычным невынашиванием беременности и хроническим эндометритом в возрасте от 21 до 41 года, 
Таблица 1. Алгоритм проведения врачебных визитов в исследовании.

\begin{tabular}{|c|c|c|}
\hline Этап исследования & Срок исследования & Описание алгоритма действий \\
\hline 1-й визит & \multirow[t]{4}{*}{$\begin{array}{l}\text { 1-й месяц } \\
\text { наблюдения }\end{array}$} & $\begin{array}{l}\text { скрининг, на котором перед включением пациентов в исследование (0-й } \\
\text { день) } \\
\text { проводится обследование: изучение анамнеза (наличие хронического } \\
\text { эндометрита в анамнезе, аборты; } \\
\text { внутриматочные инвазивные манипуляции (выскабливание полости матки, } \\
\text { введение или извлечение ВМК); бесплодие; привычное невынашивание, } \\
\text { длительность заболевания, сведений о сопутствующих заболеваниях и } \\
\text { сопутствующей терапии), оценка общих } \\
\text { показателей (ЧСС, АД, температура тела), бимануальное исследование }\end{array}$ \\
\hline 2-й визит & & УзИ органов малого таза на 5-7дни менструального цикла \\
\hline 3-й визит & & $\begin{array}{l}\text { На 9-10 менструального цикла биопсия эндометрия (вакуум-аспирация } \\
\text { эндометрия мануальным вакуум-аспиратором Pentcraft) с последующим } \\
\text { микробиологическим (Фемофлор) и иммуногистохимическим (синдекан-1) } \\
\text { анализом состава полости матки, кофокусный анализ экспресси TLR9 }\end{array}$ \\
\hline 4-й визит & & УзИ органов малого таза на 22-24 день менструального цикла \\
\hline 5-й визит & $\begin{array}{l}\text { 2-й месяц } \\
\text { наблюдения }\end{array}$ & $\begin{array}{l}\text { применение терапии согласно глруппе больных с 1-го дня менструального } \\
\text { цикла }\end{array}$ \\
\hline 6-й визит & \multirow{3}{*}{$\begin{array}{l}\text { 3-й месяц } \\
\text { наблюдения }\end{array}$} & УзИ органов малого таза на 5-7 день менструальнго цикла \\
\hline 7-й визит & & $\begin{array}{l}\text { На 9-10 менструального цикла биопсия эндометрия (вакуум-аспирация } \\
\text { эндометрия мануальным вакуум-аспиратором Реntcraft) с последующим } \\
\text { микробиологическим (Фемофлор) и иммуногистохимическим (синдекан-1) } \\
\text { анализом состава полости матки, кофокусный анализ экспресси TLR9 }\end{array}$ \\
\hline 8-й визит & & УзИ органов малого таза на 22-24 день менструального цикла \\
\hline 9-й визит & 4-6й месяцы наблюдения & 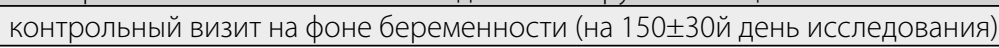 \\
\hline
\end{tabular}

которым проводилось стандартное антибактериальное лечение без комплексного применения иммуномодулирующей терапии. Антибактериальные препараты применяются согласно результатам бактериологического исследования по утвержденным схемам лечения

ЗППП (КП утвержденных Экспертной комиссией, протокол № 10 от 4 июля 2014 года).

Морфологические методы исследования включали в себя: биопсия эндометрия вакуум - аспирация эндометрия мануальным вакуум аспиратором Pentcraft); исследование биоценоза урогенитального тракта у женщин репродуктивного возраста методом ПЦР с детекцией результатов в режиме реального времени (Фемофлор); иммуногистохимический анализ (синдекан-1) биопсийного материала полости матки; кофокусный иммуногистохимический анализ экспрессии TLR9 с помощью моноклональных антител; кофокусный иммуногистохимический анализ M1 или M2 фенотипа резидентных макрофагов с помощью моноклональных антител; кофокусный иммуногистохимический анализ PD1 с помощью моноклональных антител.

Оценка эффективности терапии на основании: восстановления репродуктивной функции (наступление беременности, благополучное протекание беременности), прироста эндометрия по данным УЗИ. Проведение статистической обработки результатов исследования осуществлялось с помощью пакетов программ Ехсе1 2010, Statistica 10.0, SPSS for Windows с использованием параметрических или не` параметрических критериев (t-критерий Стьюдента, а также критерии Манна -Уитни и Вилкоксона соответственно). Статистически значимыми считались различия при $\mathrm{p}<0,05$.

\section{Характеристика исследуемого препарата}

В исследовании оценивали клиническую эффективность препарата Деринат ${ }^{\circledast}$ (раствор для внутримышечного введения 15 мг\мл, флакон) в комплексной терапии ХЭ, ассоциированным с бесплодием у женщин репродуктивного возраста. Препарат относится к фармакотерапевтической группе: иммуномодулирующие средства, регенерант, репарант. Согласно литературным данным Деринат обладает свойствами агониста толл-подобных рецепторов 9 (Toll-like receptors 9, TLR9, CB 289). Иммуномодулирующий эффект обусловлен взаимодействием действующего вещества препарата (цитозин-гуанин (CG)) с патоген-распознающими рецепторами (TLR9) на иммунокомпетентных клетках, что приводит к последующей активации целого ряда иммунных механизмов. Прежде всего, стимуляция толл-подобных рецепторов в дендритных клетках повышает их способность влиять на дифференцировку Т-хелперов, в сторону образования Т-хелперов 2-го типа (Th2). Под влиянием Th 2 происходит дифференцировка В-лимфоцитов в плаз- 
Таблица 2. Сравнительная характеристика соотношения иммунокомпетентных клеток у пациенток в исследовании.

\begin{tabular}{|l|l|l|l|l|}
\multirow{2}{*}{ Maркеры } & \multicolumn{2}{|l|}{$\begin{array}{l}\text { Группа 1 } \\
\text { (ср. кол.-во кл./объем.плотн.) }\end{array}$} & \multicolumn{2}{|l|}{$\begin{array}{l}\text { Группа 2 } \\
\text { (ср. кол.-во кл./объем.плотн.) }\end{array}$} \\
\cline { 2 - 5 } & До лечения & После лечения & До лечения & После лечения \\
\hline CD68 & $16,8 / 11,1$ & $14,9^{*} / 9,6^{*}$ & $16,8 / 10,6$ & $16,7^{*} / 10,5^{*}$ \\
\hline CD163 & $21,7 / 13,6$ & $21,4 / 14,1^{*}$ & $21,3 / 13,2$ & $19,2 / 11,4$ \\
\hline CD138 & $1,2 / 0.8$ & $1,5^{*} / 0,9^{*}$ & $1,3 / 0,8$ & $1,2^{*} / 0,8^{*}$ \\
\hline
\end{tabular}

Примечание: * $-p<0,001$

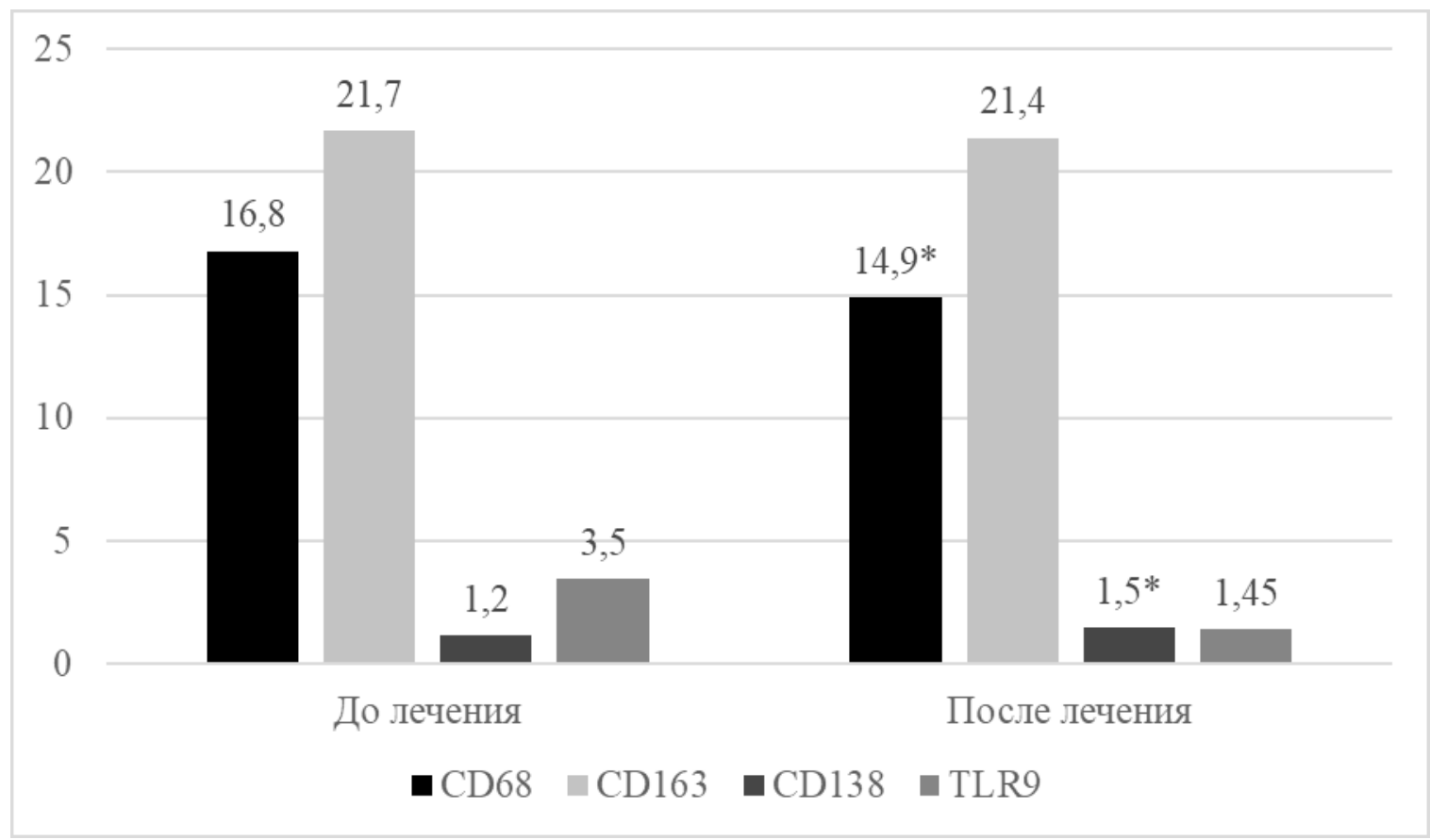

Рис. 1. Сравнительная характеристика среднего количества иммунокомпетентных клеток до и после лечения у пациентов 1 группы.

Примечание: * $-\mathrm{p}<0,001$.

матические клетки, секретирующие $\lg G 2, \lg G 4, \lg M$. А стимулируемые Деринатом через TLR9 эпителиальные клетки усиливают секрецию slgA, выполняющего как барьерную функцию, так и функцию опсонина для взаимодействия с клеточным звеном местного иммунного ответа: макрофагами и NK (17). Таким образом, стимуляция TLR9 макрофагов, а также их IFNy, приводит к активации трёх уровней макрофагального ответа и повышению репаративного потенциала клеточных структур.

\section{Результаты}

собственных исслеАований

Иммуногистохимическое исследование биопсийного материала эндометрия наглядно отражает изменение состояния макрофагов у пациенток в исследовании как до, так и после проведенной терапии. Иммуногистохимическое исследование (таблица рисунки 2,3) проводилось всем пациенткам двух групп до и после лечения. Полученные результаты показывают большую гетерогенность.

Представленные данные на рисунках и в таблице свидетельствуют о том, что количество макрофагов CD68 после применения препарата уменьшается, но при этом макрофаги CD163 демонстрируют обратную динамику. Плазмоциты CD138, несмотря на увеличение среднего числа и объемной плотности, демонстрируют выраженную негативную динамику. Количество клеток, экспрессирующих TOLL-подобные рецепторы, снижалось. 


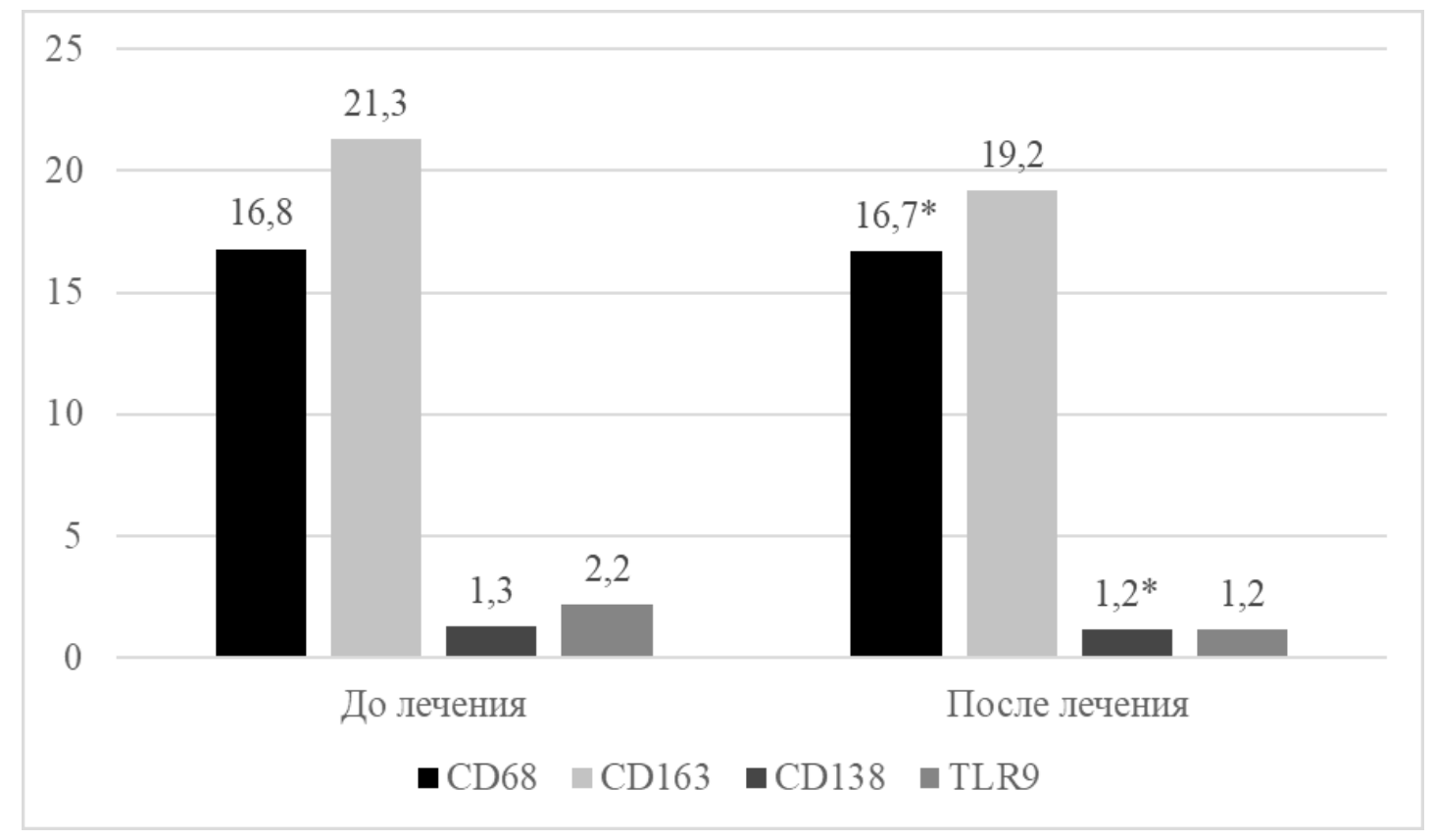

Рис. 2. Сравнительная характеристика среднего количества иммунокомпетентных клеток до и после лечения у пациентов 2 группы.

Примечание: ${ }^{*}-\mathrm{p}<0,001$.

Положительная динамика наблюдалась в 8 случаях (36\%), причем средний показатель прироста числа клеток составил 27\%. В оставшихся случаях (64\%) число клеток снижалось в среднем на 29,4\%. Положительная динамика наблюдалась в 13\% случаев (59,5\%), средний показатель увеличения числа клеток -39,4\% в остальных случаях - динамика отрицательная.

Оценить динамику изменения количества плазмоцитов удалось не во всех случаях, потому что изначально в группе до лечения эти типы клеток отсутствовали. В 10 случаях CD138 не было обнаружено вообще. После лечения появилась экспрессия плазмоцитов. Экспрессия TLR9 после применения препарата уменьшилась в 16 случаях (73\%), в остальных случаях количество клеток в среднем увеличилось на 66,5\%. Отмечено, что на фоне приема препарата Деринат существенно увеличилась количество клеток, участвующих в фагоцитарной активности макрофагов и клеточной пролиферации. После лечения у всех пациенток была получена адекватная дню цикла гистологическая картина эндометрия и отсутствие воспалительных изменений.

\section{Обсужьение результатов}

Иммунные клетки являются неотъемлемой частью патогенеза ХЭ. В работе продемонстрированы основные результаты комплексного лечения с применением препарата иммуномодулирующего действия.
Основные механизмы улучшения обусловлены следующими эффектами:

1. Предотвращение образования в эндометрии воспалительного инфильтрата, что подтверждается снижением в нем количества иммунокомпетентных клеток (CD8, CD56, CD68, CD138) и уровня провоспалительных цитокинов и факторов роста (II-1, II-6, IFN - y, TNF, TGF, VEGF и др.);

2. Нормализация регенеративных процессов в эндометрии на фоне снижения интенсивности апоптоза клеток и склеротических изменений в ткани, о чем свидетельствует восстановление показателей Ki-67, EGF, Аро-ргоtein, уровней MMPs и различных видов коллагена.

Важнейшим итогом комплексного лечения ХЭ является восстановление рецептивности эндометрия, что лежит в основе возможности успешной реализации репродуктивной функции в дальнейшем [20,21,22].

\section{Выво $\triangle \mathrm{b}$}

Результаты проведенного исследования свидетельствуют о целесообразности включения в комплексную терапию хронического эндометрита препарата Деринат, который обеспечивает длительный положительный лечебный эффект, восстанавливает основные звенья иммунитета с увеличением количества клеток, которые участвуют в фагоцитарной активности макрофагов и клеточной пролиферации. 


\section{ЛИТЕРАТУРА}

1. Унанян А.Л., Сидорова И.С., Аракелов С. Э. и др. Хронический цервицит и хронический эндометрит: общие аспекты патогенеза и патогенетической терапии // Медицинский совет.— 2013.— № 4-2.—C. 88-95.

2. Казачков Е.Л. Морфофункциональная характеристика нарушений рецептивности эндометрия при хроническом эндометрите // Архив патологии.2014. 一 № 3. - C. 53-58.

3. Amui J., Check J. H., Cohen R. Successful twin pregnancy in a donor oocyte recipient despite a maximum endometrial thickness in the late proliferative phase of 4 $\mathrm{mm} / /$ Clin. Exp. Obstet. Gynec01.—2011.—Vol. 38(4). - P. 328-329.

4. Kasius J.C., Broekmans F. J., Sie-Go Д.M., et a1. The reliability or the histological diagnosis or endometritis in asymptomatic IVF cases: a multicenter observer study // Hum. Reprod. - 2012.-Vol. 27.-P. 153-158.

5. Kasius J.C., Fatemi H. M., Bourgain C., et a1. The impact of chronic endometritis on reproductive outcome // Fertil. and Steril. — 2011. — Vol. 96(6). — P. 14511456.

6. Kumar V. CD45 Phosphatase Inhibits STAT3 Transcription Factor Activity in Myeloid Cells and Promotes Tumor-Associated Macrophage Differentiation // Immunity.2016. - № 44.- P. 303-15.

7. Senturk L.M., Ere C. T. Thin endometrium in assisted reproductive technology // Curr. Opin.0bstet. Gynecol._ 2008.—Vol. 20(3).— P. $221-228$.

8. Колмык В. А. Роль специфической иммуногистохимической методики в диагностике хронического эндометрита // Вестник российской военно-медицинской академии. - 2015. - Т. 1, № 49.

9. Боярский К.Ю., Гайдуков С. Н., Пальченко Н. А. Современный взгляд на проблему рецептивности и тонкого эндометрия в программах ВРТ: обзор литературы // Проблемы репродукции. - 2013.— - Т. 19., № 4. - C. 51-60.

10. Reynolds K., Khoury J., Sosnowski J., et a1. Comparison of the effect of tamoxifen on endometrial thickness in women with thin endometrium ( $<7 \mathrm{~mm})$ undergoing ovulation induction with clomiphene citrate // Fertil. and Steril. — 2010. — Vol. 93(6). — P. 2091-2093.

11. Волкова Е.Ю., Силантьева Е.С., Серов В.Н., и др. Влияние физиотерапии на гемодинамику матки у женщин с нарушением репродуктивной функции и «тонким» эндометрием // Российский вестник акушера-гинеколога. - 2012.— № 3. - C. 50-54.

12. Check J.H., Cohen R. Live fetus following embryo transfer in a woman with diminished egg reserve whose maximal endometrium thickness was less than $4 \mathrm{~mm} / /$ C1in. Exp. Obstet. Gynecol.— 2011. - Vol. 38. - P. 330-332.

13. Калинина Е.А., Дюжева Е. В. Применение пероральных контрацептивов в программе экстракорпорального оплодотворения // Акуш. и гин.— 2009.— № 2.- - C. 11-13.

14. Miwa I., Tamura H., Takasaki A., et a1. Pathophysiologic features of'thin' endometrium // Fertil. and Steril.— 2009.— Vol. 91(4). — P. 998-1004.

15. Takasaki A., Tamura H., Miwa l., et a1. Endometrial growth and uterine blood: a pilot study for improving endometrial thickness in the patients with a thin endometrium // Fertil. And Steril. — 2010.—Vol. 93(6). — P. 1851-1858.

16. Рудакова Е.Б., Лобода 0. А. Хронический эндометрит в аспекте результативности программ экстрстракорпорального оплодотворения // Лечащий врач.2012. - № 11.- C. 22-24.

17. Casper R. F. It's time to pay attention to the endometrium // Fertil. And Steril. — 2011. — Vol. 96. — P. 519-521.

18. Dix E., Check J. H. Successful pregnancies following embryo transfer despite very thin late proliferative endometrium // C1in. Exp. Obstet. Gyneco1.— 2010.—Vol. 37. - P. 15-16.

19. Филатов 0.Ю., Кашаева О. В., Бугримов Д. Ю., и др. Морфофизиологические принципы иммунологического действия ДНК эукариот // Российский Иммунологический журнал.—2013.- Т. 7., № 16.-С. 4.

20. Jimenez P.T., Schon S. B., Odem R. R., et a1. A retrospective crossectional study: fresh cycle endometrial thickness is a sensitivepredictor of anadequate endometrial thickness in frozen embryo transfer cycles // Reprod. Bio1ndocrinol.— 2013. - Vol. 10. - P. 35.

21. Петров Ю. А. Аспекты микробиологической и иммунной диагностики хронического эндометрита // Современные проблемы науки и образования.2016.— № 4.- - С. 9.

22. Радзинский В.Е., Петров Ю. А. Патогенетические особенности макротипов хронического эндометрита // Казанский медицинский журнал. - 2017. - Т. 98, № 1.- C. 27-34. 